J. Lake Sci. (湖泊科学) , 2017, 29(5): 1195-1201

DOI 10. 18307/2017. 0517

(C) 2017 by Journal of Lake Sciences

\title{
安徽颖州西湖省级湿地自然保护区乌类多样性
}

\author{
李永民 ${ }^{1}$, 聂传朋 $^{1}$, 王魏根 ${ }^{1}$, 黄 新 $^{1}$, 聂 $^{\text {超 }}{ }^{2}$, 袁 浩 ${ }^{2}$ \\ ( 1 : 阜阳师范学院生物与食品工程学院, 阜阳 236041) \\ (2: 安徽颖州西湖省级湿地自然保护区管理局,阜阳 236121)
}

\begin{abstract}
摘 要: 2013 年 6 月- 2015 年 6 月,对安徽颖州西湖省级湿地自然保护区内农田区、河流湿地和湖泊湿地 3 种典型生境 的鸟类进行调查, 共记录到鸟类 123 种, 属于 14 目 33 科 69 属. 按照季节和生境的不同对鸟类多样性进行分析, 结果表 明: 预州西湖湿地保护区秋季鸟类的物种数和密度显著高于其他季节, 而夏季拥有最高的物种多样性指数和均匀度指 数; 在颖州西湖湿地保护区 3 种典型生境中, 湖泊湿地的鸟类物种数显著多于河流湿地和农田区, 同时, 湖泊湿地和农田 区乌类密度、物种多样性指数、均匀度指数显著高于河流湿地, 而河流湿地拥有最高的优势度指数. 就科属水平上的多样 性而言, 该保护区乌类群落科属间多样性为 0.76 . 颖州西湖湿地是彻璚类和雁鸭类等迁徙鸟类的重要中途停歇地和越 冬地.
\end{abstract}

关键词: 颖州西湖;湿地;鸟类;多样性

\section{Avian diversity in Provincial Wetland Nature Reserve of Anhui Yingzhou West Lake}

\author{
LI Yongmin ${ }^{1}$, NIE Chuanpeng ${ }^{1}$, WANG Weigen ${ }^{1}$, HUANG Xin ${ }^{1}, \mathrm{NIE} \mathrm{Chao}^{2}$ \& YUAN Hao ${ }^{2}$ \\ (1: School of Biology and Food Engineering, Fuyang Teachers College, Fuyang 236041, P.R.China) \\ (2: Administration Bureau of Anhui Yingzhou West Lake Provincial Wetland Nature Reserve, Fuyang 236121, P.R.China)
}

\begin{abstract}
From June, 2013 to June, 2015, an investigation of bird communities had been made in habitats of farmland, river wetland and lake wetland in Yingzhou West Lake Reserve. A total of 123 species were recorded, which belong to 14 orders, 33 families and 69 genera. We analyzed the relative diversity indices. Results showed that the species number and density in autumn were higher than those in other seasons. The Shannon-Wiener index and Pielou index in summer were the highest. The species number in lake wetland was the greatest among the three habitats. The density, Shannon-Wiener index and Pielou index in lake wetland and farmland were higher than those in river wetland. At the same time, the dominance index in river wetland was the highest. In terms of diversities at family and genus, the $G-F$ index in Yingzhou West Lake Reserve was 0.76. Yingzhou West Lake Reserve is an important stopover and wintering site for shorebirds and Anatidae birds.
\end{abstract}

Keywords: Yingzhou West Lake; wetland; aves; diversity

湿地是地球上三大生态系统之一, 同时也是生物多样性最为丰富的生态系统之一 ${ }^{[1]}$. 湿地鸟类作为湿 地生态系统的消费者, 甚至是顶级消费者, 对于维持湿地生态系统的动态平衡具有重要意义 ${ }^{[2]}$. 同时, 湿地 鸟类对生态环境的变化较为敏感,因此也是湿地重要性评估和湿地环境监测的客观生物指标 ${ }^{\left[{ }^{[3]}\right.}$.

国际上湿地生物多样性的研究热点主要包括湿地珍稀鸟类的栖息地利用与保护 ${ }^{[4]}$ 、湿地生态恢复与人 工湿地构建 ${ }^{[5]}$ 、湿地生物多样性的管理与合理利用 ${ }^{[6]}$ 等方面. 国内对于湿地鸟类群落的研究起步较晚, 但发 展迅速, 目前的研究主要围绕以下几方面进行: 湿地鸟类物种组成 ${ }^{[7]} 、$ 湿地鸟类多样性 ${ }^{[8-10]}$ 、湿地鸟类栖息地 选择和修复 ${ }^{[1-1-13]}$ 、湿地鸟类迁徙生态学和繁殖生态学 ${ }^{[14-17]}$ 、新技术、新理论如“3 3 ” 技术、景观生态学在湿地

* 安徽省自然科学基金项目 (1308085MC39)、江苏省滩涂生物资源与环境保护重点建设实验室开放基金项目 (JKLBS2015003) 、安徽省教育厅自然科学研究项目 (KJ2016A873,2015KJ004,2016jyxm0751) 和阜阳师范学院博士 科研启动项目联合资助. 2016-09-02 收稿; 2016-12-09 收修改稿. 李永民(1976 ), 男, 博士, 副教授; E-mail: lyminron@163.com. 
鸟类多样性保护中的应用 ${ }^{[18]}$ 等. 淮河介于长江与黄河两大流域之间, 处于我国自然地理南北过渡带. 淮河 中游两岸分布着一连串的天然与人工湿地, 为安徽省重要的湿地区域, 流域内河渠纵横, 库塘众多, 湖泊滩 涂星罗棋布, 湿地众多, 为湿地鸟类提供了极其广阔的生态空间和诸多有利的自然条件. 目前, 对于淮河中 游湿地鸟类的研究较少, 仅见于王松等 ${ }^{[19]}$ 、鲍方印等 ${ }^{[20]}$ 和罗子君等 ${ }^{[7]}$ 对于淮河湿地鸟类群落的初步调查.

安徽颖州西湖省级湿地自然保护区地处安徽省阜阳市境内, 面积 $110 \mathrm{~km}^{2}$, 位于淮河中游左岸, 颖州西 湖是黄淮平原地区的天然永久性淡水湖泊,生态区位重要. 该湖丰水位可达 $31.5 \mathrm{~m}$ 高程, 蓄水 $1.5 \times 10^{8} \mathrm{~m}^{3}$; 平水位 $29 \mathrm{~m}$ 高程, 蓄水 $0.6 \times 10^{8} \mathrm{~m}^{3}$. 湖水向北注人泉河,随后汇人淮河左岸一级支流颖河, 在寿县正阳关注 人淮河 ${ }^{[21]}$. 该保护区兼有河流、湖泊等多种湿地类型, 湿地生态过程完整, 湿地景观优美, 湿地植物丰富, 并 且拥有深厚的历史文化资源, 是阜阳市生态环境保护和社会经济可持续发展的重要保障.

作为同属于淮河中游的重要湖泊,霍邱东西湖、寿县瓦埠湖的生态区位也很重要. 安徽霍邱东西湖省级 湿地自然保护区地处安徽省霍邱县境内, 面积 $142 \mathrm{~km}^{2}$, 位于淮河中游右岸, 其中城西湖面积 $35 \mathrm{~km}^{2}$, 湖水北 流到沿岗河至临淮岗注人淮河 ${ }^{[20]}$; 城东湖面积 $107 \mathrm{~km}^{2}$, 湖水向北注人汲河, 至溜子口汇人淮河. 安徽瓦埠 湖省级湿地自然保护区地处安徽省寿县境内, 位于淮河右岸, 是淮河中游面积最大的天然永久性淡水湖泊. 湖区正常水位 $18.0 \mathrm{~m}$, 面积 $156 \mathrm{~km}^{2}$, 蓄水 $2.2 \times 10^{8} \mathrm{~m}^{3}$. 主要来水南有东淝河, 东有瓦埠河, 西有陡涧河. 湖水 经东汁河下游北流至赵台子注人淮河 ${ }^{[20]}$.

阜阳市近年来十分重视生态保护和修复工作, 制定了建设滨水园林城市的目标, 逐步加大对颖州西湖 省级湿地保护区的保护和修复力度, 争取达到生物多样性保护与区域经济发展和谐一致的目标. 在此背景 下, 受安徽颖州西湖省级湿地自然保护区管理局的委托, 在前期鸟类资源初步调查 ${ }^{[21]}$ 的基础上进一步对颖 州西湖湿地保护区乌类群落进行深人研究, 解析不同生境和不同季节的鸟类多样性差异, 并对颖州西湖、霍 邱东西湖和寿县瓦埠湖的鸟类多样性进行比较, 以期为鸟类多样性保育与湿地管理提供科学依据.

\section{1 研究地区和研究方法}

\section{1 研究地区概况}

安徽颖州西湖省级湿地自然保护区 $\left(32^{\circ} 56^{\prime} \sim 33^{\circ} 09^{\prime} \mathrm{N}, 115^{\circ} 11^{\prime} \sim 115^{\circ} 46^{\prime} \mathrm{E}\right)$ 地处淮河平原西北部, 属典 型的淮北平原风貌. 位于我国东部季风气候区, 具有暖温带向亚热带渐变的半湿润过渡气候特征, 四季分 明, 气候温和, 雨量适中, 光照充足, 无霜期长. 保护区年平均气温 $14.9^{\circ} \mathrm{C}$, 年平均活动积温 $4857.1^{\circ} \mathrm{C}$; 常年主 导风向为偏东风, 平均风速 $2.7 \mathrm{~m} / \mathrm{s}$; 年均降雨量 $889.1 \mathrm{~mm}$, 多集中在 7-9 月,年均蒸发量 $160.2 \mathrm{~mm}$; 年平均 日照时数 $2300 \mathrm{~h}$, 无霜期 $219 \mathrm{~d}$; 颖州西湖堤坝内侧多为河流淤泥, 坝外主要是灰潮土和普通砂礧黑土亚类, 普通棕壤亚类次之 ${ }^{[21]}$. 颖州西湖属淮河流域泉河水系, 保护区内大小河道纵横交织、河沟稠密, 其中较大的 河流有泉河和草河等.

根据颖州西湖湿地保护区的生态环境和植被概况, 将该保护区划分为 3 种典型生境: 农田区、河流湿地 和湖泊湿地.

\section{2 研究方法}

1.2.1 调查方法 2013 年 6 月- 2015 年 6 月对安徽颖州西湖省级湿地自然保护区内的鸟类群落进行了调查. 调查采用样线法进行, 遵循随机性原则, 结合不同生境的具体状况设置样线, 其中农田区 3 条样线, 河流湿 地 3 条样线, 湖泊湿地 2 条样线 (图 1). 每条样线长度为 1000 2000 m. 每条样线每季节共调查 3 次.

1.2.2 统计方法 鸟类密度公式为:

$$
D=N /(2 L \cdot W)
$$

式中, $D$ 为密度, $N$ 为样线内观察到的鸟类数量, $L$ 为样线长度, $W$ 为样线单边宽度.

以 Shannon-Wiener 指数 $\left(H^{\prime}\right)$ 测度鸟类物种多样性 ${ }^{[22]}$ :

$$
H^{\prime}=-\sum_{i=1}^{S} P_{i} \cdot \ln P_{i}
$$

式中, $S$ 为物种数, $P_{i}$ 为第 $i$ 物种的个体数与所有物种个体总数的比值.

用 Pielou 指数 $(J)$ 测度均匀度 ${ }^{[22]}$ : 


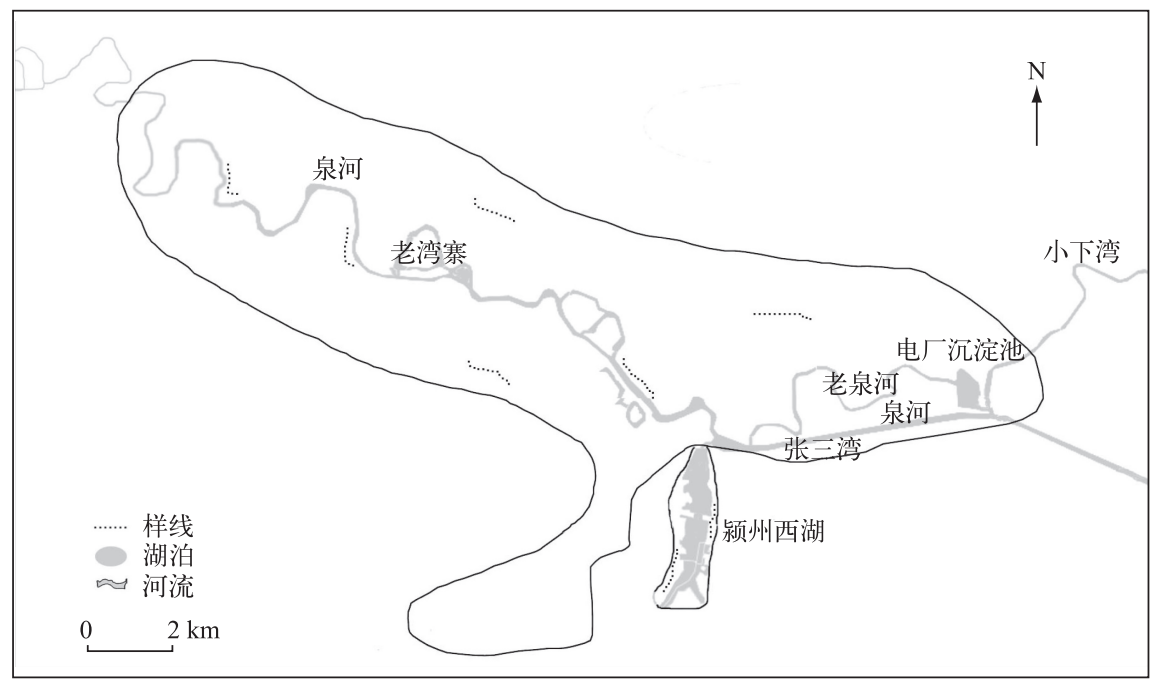

图 1 鸟类调查样线示意图

Fig.1 Sketch map of the routes for birds survey

$$
J=H^{\prime} / H_{\text {max }}^{\prime}
$$

式中, $H^{\prime}{ }_{\text {max }}$ 即 $\ln S$.

优势度指数 $(C)$ 计算公式为:

$$
C=\sum_{i=1}^{S}\left(P_{i}\right)^{2}
$$

用 $G-F$ 指数 $\left(D_{\mathrm{G}-\mathrm{F}}\right)$ 测度科属间多样性 ${ }^{[23]}$ :

$$
D_{\mathrm{G}-\mathrm{F}}=1-D_{\mathrm{G}} / D_{\mathrm{F}} ; D_{\mathrm{F}}=\sum_{k=1}^{m} D_{\mathrm{FK}} ; D_{\mathrm{FK}}=-\sum_{r=1}^{n} P_{r} \cdot \ln P_{r} ; D_{\mathrm{G}}=-\sum_{j=1}^{r} q_{j} \cdot \ln q_{j}
$$

式中, $D_{\mathrm{FK}}$ 为 $k$ 科中的物种多样性, $D_{\mathrm{F}}$ 为科间多样性, $D_{\mathrm{G}}$ 为属间多样性, $P_{r}$ 为群落中 $k$ 科 $r$ 属中的物种总数占 $k$ 科物种总数的比值, $q_{j}$ 为群落中 $j$ 属的物种数与总的物种数之比. $m$ 为群落中的科数, $n$ 为 $k$ 科中的属数, $y$ 为群落中的总属数.

对不同生境和不同季节鸟类群落进行比较时采用双因素方差分析 (Two-way ANOVA), 用 Duncan 法进 行多重比较, 以 0.05 为检验水准. 分析前对数据进行正态性和方差齐性检验, 经检验, 数据符合参数统计条 件. 以上数据分析使用数理统计软件 DPS (V7.05) ${ }^{[24]}$ 完成.

\section{2 结果与分析}

\section{1 鸟类多样性总体特征}

调查共记录到鸟类 123 种,属于 14 目 33 科 69 属. 就科属水平上的多样性而言, 颖州西湖省级湿地保护 区乌类群落 $D_{\mathrm{G}}$ 达到 $4.09, D_{\mathrm{F}}$ 达到 17.26 , 整个群落 $D_{\mathrm{G}-\mathrm{F}}$ 为 0.76 .

颖州西湖省级湿地保护区秋季鸟类的物种数和密度显著高于其他季节, 而夏季拥有最高的物种多样性 指数和均匀度指数. 就优势度指数而言, 则表现为夏季最低, 冬季最高 $($ 表 1$)$.

在颖州西湖省级湿地保护区内 3 种典型生境中, 每次调查时, 在湖泊湿地观测到的鸟类种类均显著多 于河流湿地和农田区, 同时, 湖泊湿地和农田生境鸟类密度、物种多样性指数、均匀度指数显著高于河流湿 地, 而河流湿地拥有最高的优势度指数 (表 2).

\section{2 同一生境不同季节的鸟类多样性比较}

2.2.1 农田区 鸟类物种数、密度、均匀度指数和优势度指数在不同季节波动不明显. 物种多样性指数夏季 最大, 冬季最小,差异达到显著水平 (表 3). 在夏季,农田树林是许多雀形目、鹳形目和鹃形目鸟类的重要繁 
殖地. 农田鸟类群落优势种为麻雀 (Passer montanus)、白头鹎 (Pycnonotus sinensis)、棕头鸦雀 ( Sinosuthora webbiana)、家燕 (Hirundo rustica)、珠颈斑鸠 (Spilopelia chinensis) 等.

表 1 颈州西湖省级湿地保护区不同季节多样性差异 *

Tab.1 Compare of avian diversity in Yingzhou West Lake Reserve in the four seasons

\begin{tabular}{cccccc}
\hline 季节 & $S$ & $D$ & $H^{\prime}$ & $J$ & $C$ \\
\hline 春季 & $18.33 \pm 5.02^{\mathrm{ab}}$ & $12.89 \pm 9.85^{\mathrm{b}}$ & $1.54 \pm 0.57^{\mathrm{b}}$ & $0.66 \pm 0.14^{\mathrm{ab}}$ & $0.34 \pm 0.17^{\mathrm{ab}}$ \\
夏季 & $17.11 \pm 4.99^{\mathrm{b}}$ & $14.72 \pm 7.59^{\mathrm{b}}$ & $1.95 \pm 0.56^{\mathrm{a}}$ & $0.69 \pm 0.13^{\mathrm{a}}$ & $0.25 \pm 0.16^{\mathrm{b}}$ \\
秋季 & $21.67 \pm 7.63^{\mathrm{a}}$ & $28.56 \pm 24.54^{\mathrm{a}}$ & $1.62 \pm 0.41^{\mathrm{b}}$ & $0.59 \pm 0.09^{\mathrm{b}}$ & $0.33 \pm 0.12^{\mathrm{ab}}$ \\
冬季 & $14.89 \pm 3.89^{\mathrm{b}}$ & $18.40 \pm 21.64^{\mathrm{b}}$ & $1.41 \pm 0.59^{\mathrm{b}}$ & $0.60 \pm 0.18^{\mathrm{b}}$ & $0.39 \pm 0.23^{\mathrm{a}}$ \\
\hline
\end{tabular}

* 同一列中不同小写字母表示同一指标不同季节间有显著差异 $(P<0.05)$.

表 2 颖州西湖省级湿地保护区不同生境多样性差异 *

Tab.2 Compare of avian diversity at three habitats in Yingzhou West Lake Reserve

\begin{tabular}{cccccc}
\hline 生境类型 & $S$ & $D$ & $H^{\prime}$ & $J$ & $C$ \\
\hline 农田区 & $14.42 \pm 4.17^{\mathrm{b}}$ & $14.93 \pm 7.43^{\mathrm{a}}$ & $1.86 \pm 0.41^{\mathrm{a}}$ & $0.69 \pm 0.12^{\mathrm{a}}$ & $0.27 \pm 0.12^{\mathrm{b}}$ \\
河流湿地 & $17.00 \pm 4.09^{\mathrm{b}}$ & $4.55 \pm 1.95^{\mathrm{b}}$ & $0.84 \pm 0.31^{\mathrm{b}}$ & $0.50 \pm 0.13^{\mathrm{b}}$ & $0.58 \pm 0.16^{\mathrm{a}}$ \\
湖泊湿地 & $22.58 \pm 6.11^{\mathrm{a}}$ & $10.51 \pm 4.59^{\mathrm{a}}$ & $1.94 \pm 0.44^{\mathrm{a}}$ & $0.70 \pm 0.13^{\mathrm{a}}$ & $0.23 \pm 0.13^{\mathrm{b}}$ \\
\hline
\end{tabular}

* 同一列中不同小写字母表示同一指标不同生境间有显著差异 $(P<0.05)$.

2.2 .2 河流湿地 鸟类物种数为春季 $>$ 夏季 $>$ 秋季 $>$ 冬季, 但不同季节间差异无统计学意义. 密度和物种多样 性指数为夏季最高, 冬季最低, 且差异达到显著水平. 均匀度指数在不同季节间差异显著, 其中秋季最高, 冬 季最低. 优势度指数在冬季最高, 春、夏、秋 3 个季节之间差异不明显 (表 3 ). 河流湿地鸟类群落优势种为灰 椋鸟 (Spodiopsar cineraceus)、棕头鸦雀、家燕、罗纹鸭(Anas falcata)、小䲽挀鳥( Tachybaptus ruficollis) 等.

2.2 .3 湖泊湿地 就不同季节而言, 每次调查时, 秋季调查到的鸟类物种最为丰富, 冬季物种数较少, 且差异 具有统计学意义. 鸟类密度季节变化规律为秋季>夏季 $>$ 冬季 $>$ 春季, 但各季节间差异无统计学意义. 物种多 样性指数、均匀度指数、优势度指数在不同季节之间变化不明显 (表 3 ). 湖泊湿地鸟类群落优势种为豆雁 (Anser fabalis)、绿头鸭 (Anas platyrhynchos)、斑嘴鸭 (Anas zonorhyncha)、黑水鸡(Gallinula chloropus)等, 其种 群数量均达到数百至上千只.

\section{3 同一季节不同生境的鸟类多样性比较}

2.3.1 春季 鸟类物种数在湖泊湿地最多, 农田生境最少, 但 3 种生境之间差异无统计学意义; 密度和物种多 样性指数在湖泊和农田 2 种生境较高, 相互之间差异不明显, 河流湿地显著低于前两种生境; 均匀度指数在 各生境间的差异具统计学意义, 其中农田生境最高, 河流湿地最低; 优势度指数在河流湿地显著高于湖泊湿 地和农田 (表 3 ).

2.3.2 夏季 鸟类物种数在湖泊湿地和河流湿地显著多于农田生境, 前两者之间差异不显著; 密度以农田最 高, 河流湿地最低, 3 种生境之间差异显著; 湖泊湿地和农田的鸟类物种多样性指数和均匀度指数显著高于 河流湿地,前两者之间差异不显著; 河流湿地的鸟类优势度指数显著大于湖泊湿地和农田 (表 3 ).

2.3.3 秋季 鸟类物种数在湖泊湿地显著多于农田和河流湿地; 湖泊湿地和农田的鸟类密度和物种多样性指 数显著高于河流湿地, 前两者之间差异不显著; 均匀度指数在 3 种生境之间差异不显著; 优势度指数为河流 湿地显著大于农田和湖泊湿地,后两者之间差异不显著(表 3 ).

2.3.4 冬季 鸟类物种数在 3 种生境之间差异无统计学意义; 3 种生境之间鸟类密度差异显著, 农田生境最 高, 河流湿地最低; 湖泊湿地和农田的鸟类物种多样性指数和均匀度指数显著高于河流湿地, 前两者之间差 异不显著; 河流湿地的鸟类优势度指数显著大于湖泊湿地和农田,后两者之间差异不显著 (表 3 ). 
表 3 颖州西湖省级湿地保护区 3 种生境不同季节鸟类多样性差异 *

Tab.3 Compare of avian diversity at three habitats in Yingzhou West Lake Reserve in four seasons

\begin{tabular}{|c|c|c|c|c|}
\hline 指数 & 季节 & 农田区 & 河流湿地 & 湖泊湿地 \\
\hline \multirow[t]{4}{*}{$S$} & 春季 & $14.00 \pm 3.00^{\mathrm{Aa}}$ & $19.67 \pm 1.15^{\mathrm{Aa}}$ & $21.33 \pm 6.81^{\mathrm{Aab}}$ \\
\hline & 夏季 & $11.67 \pm 1.53^{\mathrm{Ba}}$ & $18.00 \pm 1.73^{\mathrm{Aa}}$ & $21.67 \pm 4.16^{\text {Aab }}$ \\
\hline & 秋季 & $18.00 \pm 5.29^{\mathrm{Ba}}$ & $17.33 \pm 6.66^{\mathrm{Ba}}$ & $29.67 \pm 4.04^{\mathrm{Aa}}$ \\
\hline & 冬季 & $14.00 \pm 5.00^{\mathrm{Aa}}$ & $13.00 \pm 2.65^{\mathrm{Aa}}$ & $17.67 \pm 3.21^{\mathrm{Ab}}$ \\
\hline \multirow[t]{4}{*}{$D$} & 春季 & $8.75 \pm 5.80^{\mathrm{Aa}}$ & $4.31 \pm 0.61^{\mathrm{Bab}}$ & $8.17 \pm 5.47^{\mathrm{Aa}}$ \\
\hline & 夏季 & $16.64 \pm 6.61^{\mathrm{Aa}}$ & $6.78 \pm 1.52^{\mathrm{Ca}}$ & $10.20 \pm 5.37^{\mathrm{Ba}}$ \\
\hline & 秋季 & $17.57 \pm 7.71^{\mathrm{Aa}}$ & $4.21 \pm 1.95^{\mathrm{Bab}}$ & $14.40 \pm 4.08^{\mathrm{Aa}}$ \\
\hline & 冬季 & $16.76 \pm 9.48^{\mathrm{Aa}}$ & $2.87 \pm 1.55^{\mathrm{Cb}}$ & $9.25 \pm 2.62^{\mathrm{Ba}}$ \\
\hline \multirow[t]{4}{*}{$H^{\prime}$} & 春季 & $1.79 \pm 0.45^{\mathrm{Aab}}$ & $0.84 \pm 0.09^{\mathrm{Bab}}$ & $1.81 \pm 0.65^{\mathrm{Aa}}$ \\
\hline & 夏季 & $2.25 \pm 0.42^{\mathrm{Aa}}$ & $1.09 \pm 0.24^{\mathrm{Ba}}$ & $2.27 \pm 0.10^{\mathrm{Aa}}$ \\
\hline & 秋季 & $1.84 \pm 0.25^{\text {Aab }}$ & $0.97 \pm 0.16^{\text {Bab }}$ & $1.83 \pm 0.14^{\mathrm{Aa}}$ \\
\hline & 冬季 & $1.57 \pm 0.35^{\mathrm{Ab}}$ & $0.44 \pm 0.27^{\mathrm{Bb}}$ & $1.84 \pm 0.61^{\mathrm{Aa}}$ \\
\hline \multirow[t]{4}{*}{$J$} & 春季 & $0.74 \pm 0.11^{\mathrm{Aa}}$ & $0.52 \pm 0.13^{\text {Bab }}$ & $0.71 \pm 0.16^{\mathrm{ABa}}$ \\
\hline & 夏季 & $0.75 \pm 0.13^{\mathrm{Aa}}$ & $0.54 \pm 0.12^{\text {Bab }}$ & $0.77 \pm 0.06^{\mathrm{Aa}}$ \\
\hline & 秋季 & $0.66 \pm 0.12^{\mathrm{Aa}}$ & $0.59 \pm 0.02^{\mathrm{Aa}}$ & $0.60 \pm 0.04^{\mathrm{Aa}}$ \\
\hline & 冬季 & $0.60 \pm 0.13^{\mathrm{Aa}}$ & $0.36 \pm 0.14^{\mathrm{Bb}}$ & $0.73 \pm 0.21^{\mathrm{Aa}}$ \\
\hline \multirow[t]{4}{*}{ C } & 春季 & $0.25 \pm 0.11^{\mathrm{Ba}}$ & $0.57 \pm 0.08^{\mathrm{Ab}}$ & $0.26 \pm 0.15^{\mathrm{Ba}}$ \\
\hline & 夏季 & $0.18 \pm 0.09^{\mathrm{Ba}}$ & $0.48 \pm 0.13^{\mathrm{Ab}}$ & $0.14 \pm 0.02^{\mathrm{Ba}}$ \\
\hline & 秋季 & $0.28 \pm 0.10^{\mathrm{Ba}}$ & $0.50 \pm 0.08^{\mathrm{Ab}}$ & $0.26 \pm 0.02^{\mathrm{Ba}}$ \\
\hline & 冬季 & $0.36 \pm 0.14^{\mathrm{Ba}}$ & $0.76 \pm 0.18^{\mathrm{Aa}}$ & $0.27 \pm 0.23^{\mathrm{Ba}}$ \\
\hline
\end{tabular}

* 同一列中不同小写字母表示同一指标不同季节间有显著差异 $(P<0.05)$, 同一行中不同大写字母表示同一指标不同生 境间有显著差异 $(P<0.05)$.

\section{3 讨论与结论}

\section{1 秋季是该区乌类保护的重要季节}

就不同季节而言,颖州西湖省级湿地保护区秋季鸟类的物种数最多、密度最大,夏季鸟类的物种多样性 指数最高、优势度指数最低. 根据中途停歇生态学 ( stopover ecology) 理论, 许多鸟类尤其是衍鵤类在长距离 迁徙过程中, 能量消耗巨大, 鸟类在迁徙途中需要在一系列的中途停歇地休息受食以恢复体力、补充能量, 中途停歇地是鸟类迁徙过程中的重要驿站 ${ }^{[25-27]}$. 作为黄淮平原地区重要的永久性淡水湖泊,在春、秋季节, 颖州西湖湿地是微璚类迁徙途中的重要停歇地和能量补充地; 在夏季, 是许多雀形目、鹳形目和鹃形目鸟类 的重要繁殖地; 在冬季, 又是许多雁鸭类水鸟的重要越冬地. 秋季鸟类物种数和密度虽然较大, 但是秋、冬季 节许多鸟类表现出较强的集群行为,造成秋、冬季节颖州西湖保护区鸟类群落的多样性指数和均匀度指数 较低, 而优势度指数较高. 秋季是该区乌类保护的重要季节.

\section{2 湖泊湿地是该区乌类保护的重点区域}

在颖州西湖省级湿地保护区 3 种生境中, 湖泊湿地的鸟类物种数、密度、物种多样性指数和均匀度指数 均较高. 根据岛屿生物地理学 (island biogeography) 理论, 斑块面积与鸟类多样性有密切关系 ${ }^{[28]}$, 水体与裸露 浅滩的面积越大, 容纳的湿地鸟类就越多 ${ }^{[7,9]}$. 在颖州西湖保护区 3 种生境中, 由于湖泊湿地水域开阔、水位 稳定、水质良好, 再加上优越的地理位置和丰富的水生植物资源, 为涉禽和游禽等迁徙或越冬鸟类提供了适 宜的栖息环境,湖泊湿地鸟类群落结构最为稳定. 湖泊湿地是鸟类保护的重点区域.

\section{3 颖州西湖在淮河流域湿地鸟类保护方面的地位}

根据王松等 ${ }^{[19]}$ 对淮河流域 (安徽段) 重要湖泊湿地鸟类资源所做的初步调查可知, 淮河流域 (安徽段) 重要湿地分布有鸟类 15 目 48 科,共计 146 种. 本次调查表明,颖州西湖省级湿地保护区鸟类种数占淮河流 
域 (安徽段) 湿地鸟类的 $84.2 \%$. 作为同属于淮河中游的重要湖泊湿地, 霍邱东西湖鸟类 67 种, 鸟类群落 $D_{\mathrm{G}}$ 达到 $3.58, D_{\mathrm{F}}$ 达到 7.14, 整个群落 $D_{\mathrm{G}-\mathrm{F}}$ 为 0.50 ; 寿县瓦埠湖鸟类 51 种, 鸟类群落 $D_{\mathrm{G}}$ 达到 $3.27, D_{\mathrm{F}}$ 达到 5.39 , 整个群落 $D_{\mathrm{G}-\mathrm{F}}$ 为 $0.39^{[19]}$. 相对而言, 颖州西湖省级湿地保护区鸟类无论在物种多样性还是在科属多样性上 均较为丰富. 显示出预州西湖在淮河流域湿地鸟类保护方面的重要作用.

\section{4 颖州西湖湿地现状及湿地鸟类多样性保护建议}

迁徙鸟类对中途停歇地的选择与该湿地的生态环境和食物可获取程度密切相关 ${ }^{[29]}$, 另外, 人类活动也 是影响迁徙鸟类中途停歇地选择的重要因素 ${ }^{[30]}$. 永州西湖湿地目前面临的主要威胁因素包括网箱养殖、外 来物种人侵、农业面源污染和人为干扰等.

预州西湖湿地生态环境的保护与修复工作对于迁徙鸟类具有重要意义, 通过营造多样化的湿地类型, 可以为行敄类等涉禽和雁鸭类等游禽提供更高质量的受食和掩蔽场所, 同时严格管理渔业捕捞和网箱养 殖,严格控制有害生物的蔓延,减少农业面源污染和人为干扰以吸引更多湿地鸟类来此停歇、越冬.

\section{4 参考文献}

[ 1 ] Mitsch WJ, Gosselink JG eds. Wetlands (third edition). New York: John Wiley and Sons, 2000.

[ 2 ] Savard JPL, Clergeau P, Mennechez G. Biodiversity concepts and urban ecosystems. Landscape and Urban Planning, $2000,48(3 / 4): 131-142$.

[ 3 ] Pertti K. Birds as a tool in environmental monitoring. Annals of Zoological Fennica, 1989, 26(3) : 153-166.

[ 4 ] Sikdar PK, Mondal S, Saha L et al. Environmental impact assessment of a proposed info-tech complex in East Calcutta wetlands. Environmentalist, 2002, 22(3) : 241-260.

[ 5 ] Marburger JE. Volunteers monitor bird use of wetland restoration on public lands in Central Florida. Ecological Restoration, $2002,20(3): 164-172$.

[ 6 ] Mori AS. Ecosystem management based on natural disturbances: hierarchical context and non-equilibrium paradigm. Journal of Applied Ecology, 2011, 48(2) : 280-292.

[ 7 ] Luo Zijun, Zhou Lizhi, Gu Changming. Summer bird diversity of the major wetlands in Fuyang City. Ecological Science, 2012, 31(5) : 530-537. [ 罗子君, 周立志, 顾长明. 阜阳市重要湿地夏季鸟类多样性研究. 生态科学, 2012, 31 (5) : 530-537.]

[ 8 ] Gong Lei, Zhang Lili, Zhou Lizhi et al. Bird diversity in summer in Anqing floodplain wetlands, middle-lower reaches of the Yangtze River. J Lake Sci, 2013, 25 (6) : 872-882. DOI : 10.18307/2013.0611. [宫蕾, 张黎黎, 周立志等. 长江中 下游安庆沿江湖泊湿地夏季鸟类多样性调查. 湖泊科学, 2013, 25(6): 872-882.]

[ 9 ] Yang Eryan, Zhou Lizhi, Fang Jianmin. Diversity and seasonal variations of avian community on the Yangtze River beach, Anqing, China. Scientia Silvae Sinicae, 2014, 50(4) : 77-83. [杨二艳, 周立志, 方建民. 长江安庆段滩地鸟类群落 多样性及其季节动态. 林业科学, 2014, 50(4) : 77-83.]

[10] Wang Song, Chang Li, Gao Fei et al. Species diversity and seasonal dynamics of waterbirds in Yingzhou Xihu Wetland Nature Reserve, Anhui. Wetland Science, 2015, 13(5): 616-621. [王松, 常丽, 高飞等. 安徽颖州西湖湿地自然保护区 水鸟多样性及季节动态. 湿地科学, $2015,13(5)$ : 616-621.]

[11] Ge Zhenming, Wang Tianhou, Shi Wenyu et al. Seasonal change and habitat selection of shorebird community at the south Yangtze River Mouth and north Hangzhou Bay. Acta Ecologica Sinica, 2006, 26(1): 40-47. [葛振鸣, 王天厚, 施文或 等. 长江口杭州湾鸭形目鸟类群落季节变化和生境选择. 生态学报, 2006, 26(1): 40-47.]

[12] Gao Wei, Lu Jianjian. A restoration trial of bird habitat on the intertidal flats in the Yangtze Estuary and its short-term effects. Acta Ecologica Sinica, 2008, 28(5): 2080-2089. [高伟, 陆健健. 长江口潮滩湿地鸟类适栖地营造实验及短 期效应. 生态学报, 2008, 28(5): 2080-2089.]

[13] Lu Changhu, Tang Jian, Yuan Anquan. Wader bird community in winter and spring at fish ponds in Hongzehu Lake Wetlands. Chinese Journal of Zoology, 2008, 43(1): 56-62. [鲁长虎, 唐剑, 袁安全. 洪泽湖冬春季鱼塘生境中鸭敄类 群落特征与栖息模式. 动物学杂志, $2008,43(1): 56-62$.

[14] Tang Chengjia, Lu Jianjian. A Study on ecological characteristics of community of the migrating waders in wetlands insides cofferdam near the Pudong National Airport. Chinese Journal of Zoology, 2002, 37(2): 27-33. [唐承佳, 陆健健. 围崖 
堤内迁徙行璚群落的生态学特性. 动物学杂志, 2002, 37(2) : 27-33.]

[15] Hou Yinxu, Zhou Lizhi, Yang Chen et al. Disturbance to the Oriental White Stork (Ciconia boyciana) breeding in the wintering area. Zoological Research, 2007, 28(4) : 344-352. [侯银续, 周立志, 杨陈等. 越冬地东方白鹳的繁殖干 扰. 动物学研究, 2007, 28(4) : 344-352.]

[16] Li Yongmin, Nie Chuanpeng, Liu Shengjie et al. Nest site characteristics of three heron species in Wuhu and adjacent regions. Chinese Journal of Ecology, 2008, 27(8): 1430-1433. [李永民, 聂传朋, 刘生杰等. 芜湖市及附近地区三种 鹭鸟巢址特征. 生态学杂志, 2008, 27(8) : 1430-1433.]

[17] Li Yongmin, Nie Chuanpeng. Nest site characteristics of Chinese pond-herons in Fuyang. Journal of Fuyang Teachers College: Natural Science, 2014, 31(1) : 42-45. [李永民, 聂传朋. 阜阳市池鹭巢址特征分析. 阜阳师范学院学报: 自 然科学版, 2014, 31(1): 42-45.]

[18] Liu Jiping, Lü Xianguo. Study on the spatial pattern of wetland bird richness and hotspots in Sanjiang Plain. Acta Ecologica Sinica, 2011, 31(20): 5894-5902. [刘吉平, 吕宪国. 三江平原湿地鸟类丰富度的空间格局及热点地区保护. 生态 学报, $2011, \mathbf{3 1}(20): 5894-5902$.]

[19] Wang Song, Bao Fangyin, Zheng Wen et al. Biodiversity on birds of important wetlands in Huaihe river basin in Anhui, China. Journal of Huazhong Normal University: Natural Sciences, 2009, 43(4) : 652-659. [王松, 鲍方印, 郑文等. 淮 河流域(安徽段)重要湿地鸟类多样性研究. 华中师范大学学报: 自然科学版, 2009, 43(4) : 652-659.]

[20] Bao Fangyin, Wang Song, Wang Mei et al. Field survey on wetland waterbird in Huaihe River basin in Anhui, China. Chinese Journal of Zoology, 2011, 46(4) : 117-125. [ 鲍方印, 王松, 王梅等. 安徽沿淮湖泊湿地水鸟资源调查. 动物学 杂志, 2011, 46(4): 117-125.]

[21] Li Yongmin, Jiang Shuanglin, Nie Chao et al. Preliminary investigation on the bird community in Yingzhou West Lake Provincial Wetland Nature Reserve. Sichuan Journal of Zoology, 2010, 29(2): 240-243. [李永民, 姜双林, 聂超等. 安徽 颖州西湖省级湿地自然保护区乌类资源调查初报. 四川动物，2010，29(2)：240-243.]

[22] Ma Keping, Liu Yuming. Measurement method I for biological community diversity : Alpha diversity measurement method (the second half). Chinese Biodiversity, 1994, 2(4): 231-239. [马克平, 刘玉明. 生物群落多样性的测度方法 I: $\alpha$ 多样性的测度方法(下). 生物多样性, 1994, 2(4) : 231-239.]

[23] Jiang Zhigang, Ji Liqiang. Avian-mammalian species diversity in nine representative sites in China. Chinese Biodiversity, 1999, 7 (3) : 220-225. [蒋志刚, 纪力强. 乌兽物种多样性测度的 G-F 指数方法. 生物多样性, 1999, 7 (3)： 220-225.]

[24] Tang Qiyi, Feng Mingguang eds. DPS data processing system for practical statistics. Beijing: Science Press, 2002. [唐启 义, 冯明光. 实用统计分析及其 DPS 数据处理系统. 北京: 科学出版社, 2002.]

[25] Farmer AH, Parent AH. Effects of the landscape on shorebird movements at spring migration stopovers. Condor, 1997, 99 (3) : 698-707.

[26] Hedenstrom A, Alerstam T. Optimum fuel loads in migratory birds: distinguishing between time and energy minimization. Journal of Theoretical Biology, 1998, 189(3): 227-234.

[27] Schaub M, Jenni L. Fuel deposition of three passerine bird species along the migration route. Oecologia, 2000, 122(3): 306-317.

[28] Chen Shuihua, Ding Ping, Zheng Guangmei et al. The richness of island habitat avian communities and their influencing factors. Acta Ecologica Sinica, 2002, 22(2) : 141-149. [ 陈水华, 丁平, 郑光美等. 岛屿栖息地鸟类群落的丰富度及 其影响因子. 生态学报, 2002, 22(2): 141-149.]

[29] Wilson WHJ. Relationship between prey abundance and foraging site selection by Semipalmated sandpipers on a bay of Fundy mudflat. Journal of Field Ornithology, 1990, 61: 9-19.

[30] Shepherd PCF, Boates JS. Effects of a commercial baitworm harvest on Semipalmated sandpipers and their prey in the Bay of Fundy hemispheric shorebird reserve. Conservation Biology, 1999, 13(2) : 347-356. 